\title{
Cerebellar atrophy and prognosis after temporal lobe resection
}

\author{
U Specht, T May, R Schulz, M Rohde, A Ebner, R C Schmidt, M Schütz, P Wolf
}

\begin{abstract}
Objective-Experimental data indicate inhibitory effects of the cerebellum on seizure activity. Structural damage such as cerebellar atrophy, which is a common finding in patients with chronic epilepsy, may reduce these effects.

Methods-Outcome after temporal lobectomy was studied in 78 consecutive patients, with or without cerebellar atrophy diagnosed by MRI.
\end{abstract}

Results-Thirty five patients (45\%) showed cerebellar atrophy. At a mean follow up of 14.6 (range, 6-40) months, 50 patients $(64 \%)$ had no postoperative seizures. In these patients, the frequency of cerebellar atrophy was significantly lower $(34 \%)$ than in patients who relapsed $(64 \%, p<0.01)$. Occurrence of generalised tonic-clonic seizures (GTCS) within two years before surgery, occurrence of GTCS at any time preoperatively, long duration of epilepsy, and older age at surgery were also associated with recurrence of seizures. Multiple logistic regression analysis suggested occurrence of GTCS within two years before surgery and cerebellar atrophy as the main predictive indicators. When both factors were present, the percentage of patients remaining seizure free since surgery fell to $30 \%$, compared with $60 \%$ when only GTCS were present, $78 \cdot 6 \%$ when only cerebellar atrophy was present, and $87 \cdot 5 \%$ when both factors were absent.

Conclusions-Cerebellar atrophy shown by MRI was a frequent finding in surgically treated patients with temporal lobe epilepsy. The presence of cerebellar atrophy seems to worsen the prognosis after temporal lobe resection.

(F Neurol Neurosurg Psychiatry 1997;62:501-506)

Keywords: cerebellar atrophy; temporal lobe resection; epilepsy

Cerebellar atrophy and loss of Purkinje cells have been reported for more than 70 years in patients with chronic epilepsy..$^{1-4}$ Figures on the frequency of cerebellar atrophy vary considerably, depending on evaluation methodology and patient selection. ${ }^{5-8}$ Studies using MRI showed a rate of about $30 \%$ in patients with chronic focal epilepsy. ${ }^{89}$ Cerebellar atrophy has usually been considered as a consequence of recurrent seizures, their treatment with phenytoin (PHT), or other epilepsy related factors. ${ }^{4810-12}$ Several experiments with animals ${ }^{13-18}$ as well as findings in human ${ }^{1920}$ suggest inhibitory effects of the cerebellum on seizure activity. A structurally damaged cerebellum may be limited in its inhibitory function and therefore may have a negative influence on the prognosis of the epilepsy. To investigate this hypothesis, we used MRI to study a cohort of patients with medically refractory temporal lobe epilepsy who underwent a temporal lobe resection.

\section{Patients and methods}

PATIENTS

Ninety patients underwent temporal lobe resection at the Bethel Epilepsy Centre, Germany, between June 1991 and June 1994.

All had complex partial seizures (CPS) with or without generalised tonic-clonic seizures (GTCS). Twelve patients were excluded because of previous surgery (three), incomplete resection (three), incomplete or lost MRI studies (four), progressive brain tumour (one), or multiple lesions (one). Mean (SD) age at operation of the remaining 38 women and 40 men was 29.9 (13) (range 3.5-60) years. The diagnosis of temporal lobe epilepsy was based on seizure history, neurological examination, long term EEG/video monitoring, MRI and PET studies, neuropsychological testing, and an intracarotid amobarbital test. Eighteen patients had invasive recordings with epidural peg and foramen ovale electrodes (11) or depth electrodes (seven). Seventy five patients underwent a polar resection with extensive amygdalar and hippocampal resection ("keyhole approach") or a standard anterior temporal lobectomy. ${ }^{21}$ In three patients with circumscribed lesions in the lateral temporal neocortex a lesionectomy was performed.

FOLLOW UP

Patients were followed up six months and two years after surgery for assessment of seizure control and neuropsychological and psychosocial outcome. Patients who had not been evaluated within the previous 12 months were contacted by telephone. All patients had at least six months of follow up.

EVALUATION BY MRI

The first assessment six months postoperatively included an MRI study; this MRI was chosen for evaluation of cerebellar atrophy, because unrecognised hypoxia during surgery might have caused additional cerebellar damage. In 
Figure 1 Four MR images in the sagittal plane, presenting four different degrees of cerebellar atrophy in the upper vermis. Top left, no atrophy (patient aged 16 years). Top right, mild atrophy (patient aged 25 years). Bottom left, moderate atrophy (patient aged 28 years). Bottom right, severe atrophy (patient aged 25 years). Note that mild atrophy was considered normal, unless one of the radiologists rated moderate different region of the cerebellum. or severe atrophy in a
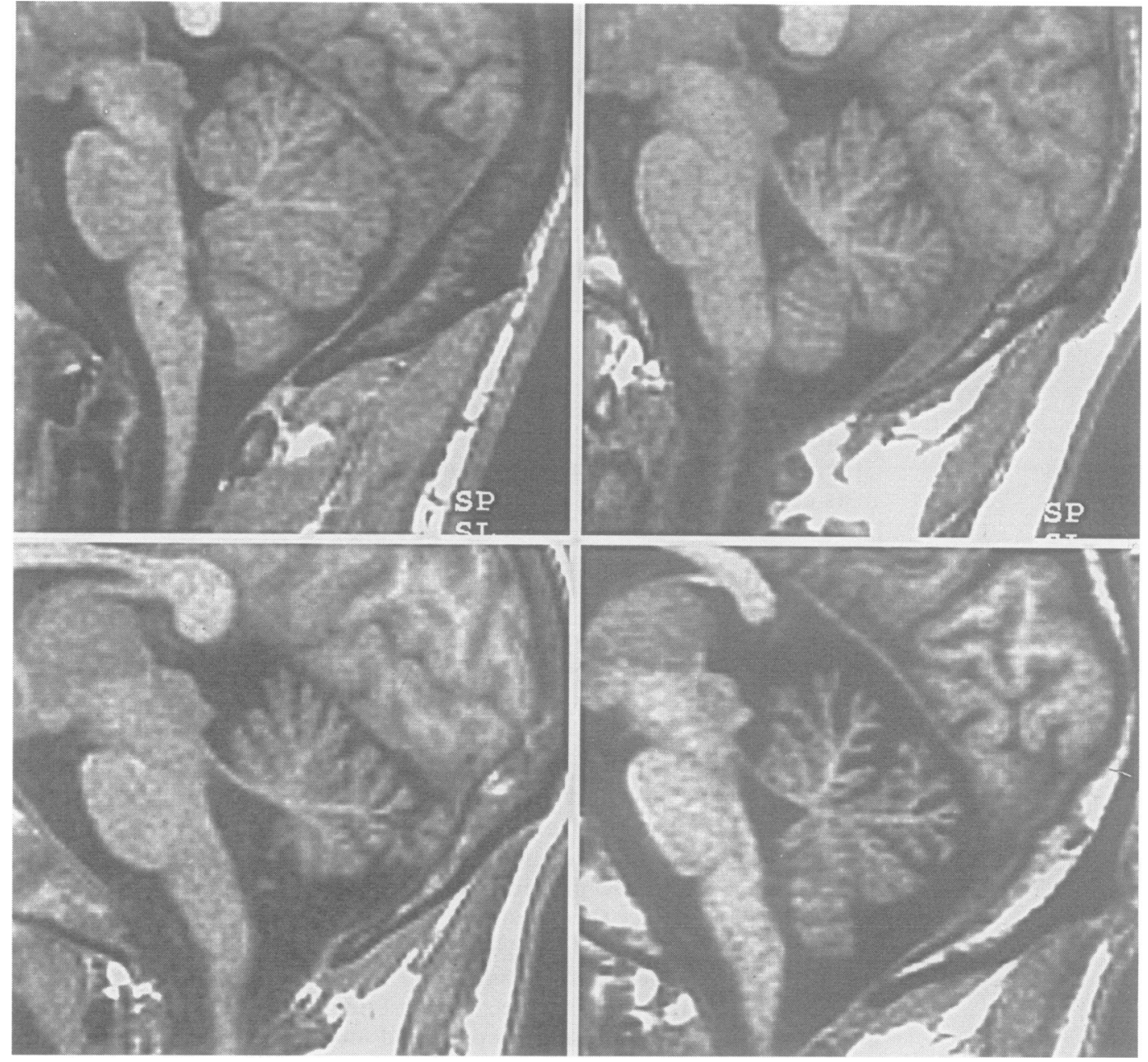

six patients without postoperative MRI, the last MRI before surgery was examined. In these patients, a careful review of the surgical, anaesthesiology, and intensive care notes gave no evidence for any complication, including hypoxia during surgery. In 52 patients, a 1.0 Tesla Magnetom Impact (Siemens AG, Erlangen, Germany) was used. Scanning was performed using an epilepsy protocol in the coronal and axial plane with T2 weighting (TE/TR 85/3500 $\mathrm{ms}$ ), and in the axial plane with proton density $(17 / 3500 \mathrm{~ms})$, generating images which were 5 $\mathrm{mm}$ thick with an interslice gap of $1.5 \mathrm{~mm}$. Axial, coronal, and sagittal $3 \mathrm{~mm}$ thick slices were also obtained using 3D FLASH sequences with T1 weighting $(5 / 18 \mathrm{~ms})$. Most of the 26 earlier scans were performed on a 1.5 Tesla

Table 1 Variables associated with cerebellar atrophy (univariate analysis)

\begin{tabular}{|c|c|c|c|}
\hline & $\begin{array}{l}\text { Patients without } \\
\text { cerebellar atrophy } \\
(n=43)\end{array}$ & $\begin{array}{l}\text { Patients with } \\
\text { cerebellar atrophy } \\
(n=35)\end{array}$ & Pvalue \\
\hline \multicolumn{2}{|l|}{ Occurrence of GTCS within 2 years } & $20(58 \cdot 8 \%)$ & 0.066 \\
\hline $\begin{array}{l}\text { Occurrence of GTCS at any time } \\
\text { before surgery }\end{array}$ & $24(55 \cdot 8 \%)$ & $28(80 \%)$ & 0.021 \\
\hline Duration of epilepsy (mean y (SD)) & $15 \cdot 4(9 \cdot 0)$ & $23 \cdot 4(11 \cdot 4)$ & $<0.001$ \\
\hline Age at surgery (mean y (SD)) & $26 \cdot 3(12 \cdot 6)$ & $34 \cdot 4(12 \cdot 1)$ & 0.002 \\
\hline \multicolumn{4}{|l|}{ Frequency of CPS before surgery } \\
\hline Intellectual impairment (WAIS-R) & $5(11 \cdot 6 \%)$ & $12(34 \cdot 3 \%)$ & 0.02 \\
\hline Onset of epilepsy (mean y (SD)) & $10.9(10.4)$ & $11 \cdot 0(8 \cdot 5)$ & $0 \cdot 37$ \\
\hline
\end{tabular}

GTCS = generalised tonic-clonic seizures; CPS = complex partial seizures.

^No information available in five patients.

†As the distribution of frequency of CPS deviated considerably from normal, median and $25 \%$ to $75 \%$ quartiles $(Q)$ are given.
Siemens Magnetom unit, with sagittal T1 images $(15 / 600 \mathrm{~ms})$, coronal and axial $\mathrm{T} 2$ images $(90 / 2500 \mathrm{~ms})$, and proton weighted axial images $(15 / 2500 \mathrm{~ms})$. Slice thickness in these scans was $6 \mathrm{~mm}$ in the coronal and sagittal planes and $8 \mathrm{~mm}$ in the axial planes.

All MRI was independently rated by two experienced neuroradiologists (RCS, MS), who were blind to the clinical data except age. The degree of cerebellar atrophy was scored from 0 (no atrophy) to 3 (severe atrophy) for upper and lower vermal regions and the cerebellar hemispheres (fig 1). If there was a difference of more than one degree of atrophy between the two ratings, the scans were presented to both radiologists again, who then came to a final agreement. The scores were identical in 145 of 234 instances $(62 \%$; three rating scores per patient). They differed by one degree in 87 instances $(37 \cdot 2 \%$ : between a rating of 0 and 1 $23 \cdot 1 \% ; 1$ and $211 \cdot 5 \% ; 2$ and $32 \cdot 6 \%$ ), and by two degrees in two instances $(0.9 \%)$. With the same rating scale, the degree of cerebral atrophy was assessed. Because mild cerebellar atrophy has been found in normal subjects, ${ }^{8}$ a patient was considered to have definite cerebellar atrophy if one of the neuroradiologists rated moderate or severe atrophy (score $\geqslant 2$ ) in at least one region of the cerebellum. With respect to this judgement (no cerebellar atrophy $\mathrm{v}$ definite cerebellar atrophy), there was a substantial agreement between the examiners ( $\kappa$ coefficient $0 \cdot 61) .^{22}$ Localisable lesions had been classified 
Table 2 Variables associated with outcome after temporal lobe resection (univariate analysis)

\begin{tabular}{|c|c|c|c|}
\hline & $\begin{array}{l}\text { Patients with no seizures } \\
\text { since surgery* } \\
(n=50)\end{array}$ & $\begin{array}{l}\text { Patients with at least one } \\
\text { seizure since surgery } \\
(n=28)\end{array}$ & Pvalue \\
\hline $\begin{array}{l}\text { Cerebellar atrophy in MRI } \\
\text { Occurrence of GTCS within } 2 \text { years }\end{array}$ & $17(34 \cdot 0 \%)$ & $18(64 \cdot 3 \%)$ & 0.0095 \\
\hline $\begin{array}{l}\text { before surgeryt } \\
\text { Occurrence of GTCS at any time }\end{array}$ & $15(31.9 \%)$ & $20(76 \cdot 9 \%)$ & 0.0002 \\
\hline $\begin{array}{l}\text { before surgery } \\
\text { Duration of epilepsy (mean y (SD)) } \\
\text { Age at surgery (mean y SD)) }\end{array}$ & $\begin{array}{l}27(54 \cdot 0 \%) \\
17 \cdot 2(11 \cdot 1) \\
27 \cdot 8(13 \cdot 0)\end{array}$ & $\begin{array}{l}25(89 \cdot 3 \%) \\
22 \cdot 2(9 \cdot 8) \\
33 \cdot 8(12 \cdot 2)\end{array}$ & $\begin{array}{l}0.0015 \\
0.014 \\
0.042\end{array}$ \\
\hline $\begin{array}{l}\text { Frequency of CPS before surgery } \\
\text { (median per month; }(\mathrm{Q} 25 \%-\mathrm{Q} 75 \%)) \ddagger \\
\text { Recognisable lesion in MRI } \\
\text { Mesiotemporal sclerosis in MRI } \\
\text { Cerebal atrophyS }\end{array}$ & $\begin{array}{l}6 \cdot 0(3 \cdot 3-11 \cdot 0) \\
26(52 \cdot 0 \%) \\
14(28 \cdot 0 \%) \\
8(16 \cdot 0 \%)\end{array}$ & $\begin{array}{l}8 \cdot 3(4 \cdot 0-10 \cdot 0) \\
11(39 \cdot 3 \%) \\
8(28 \cdot 6 \%) \\
5(17 \cdot 9)\end{array}$ & $\begin{array}{l}0 \cdot 28 \\
0 \cdot 2 \\
0 \cdot 96 \\
0 \cdot 83\end{array}$ \\
\hline
\end{tabular}

GTCS = generalised tonic-clonic seizures; CPS = complex partial seizures.

*With or without isolated auras.

+ No information available in five patients.

$\ddagger$ As the distribution of frequency of CPS deviated considerably from normal, median and $25 \%$ to $75 \%$ quartiles (Q) are given.

fOs the distribution of frequency of CPS deviated considerably from norm
jOnly

before surgery and were not re-evaluated for this study: 22 patients $(26.5 \%)$ had mesiotemporal sclerosis, $22(26.5 \%)$ had low grade gliomas, $14(23 \%)$ had non-tumourous lesions, and $20(24 \%)$ had no lesion in the preoperative MRI.

\section{OUTCOME MEASURES}

We compared patients who were completely seizure free since surgery-with or without isolated auras (group SF) - with those who experienced at least one seizure postoperatively (group NSF). Seizures occurring in the two weeks after surgery ("neighbourhood seizures") were not considered for outcome analysis.

\section{STATISTICAL ANALYSIS}

Data were analysed with the SPSS statistical package version $6 \cdot 1$ for Windows (SPSS Inc, Chicago, IL, USA). Fisher's exact test, MannWhitney $U$ test, and $\chi^{2}$ tests were used for univariate analysis. A $P$ value $<0.05$ was considered significant. Each variable with significant influence in the univariate analyses was included in a stepwise multiple logistic regression procedure to evaluate the relative importance of each of these factors. Variables significant at the $0 \cdot 10$ level were allowed to enter the model.

\section{Results}

FREQUENCY OF CEREBELLAR ATROPHY

Thirty five patients (45\% (95\% confidence interval (95\% CI): $33 \cdot 6-56 \cdot 6 \%)$ ) showed a moderate or severe cerebellar atrophy in at least one region of the cerebellum. In three of these patients $(8.6 \%)$, permanent ataxia had been documented in the neurological examination, whereas no patient without cerebellar atrophy presented with ataxia. Moderate or

Table 3 Predictive variables for recurrence of seizures after temporal lobe resection (multiple logistic regression analysis)

\begin{tabular}{ll}
\hline Variables & P value \\
\hline Occurrence of GTCS within 2 years before surgery & 0.001 \\
Cerebellar atrophy in MRI & 0.068 \\
Occurrence of GTCS at any time before surgery & NS $(0.55)$ \\
Longer duration of epilepsy & NS $(0.94)$ \\
Higher age at surgery & NS $(0.37)$ \\
\hline
\end{tabular}

GTCS = generalised tonic-clonic seizures; CPS = complex partial seizures; NS = not significant at $0 \cdot 10$ level; therefore not included in "model" derived from multivariate calculation.

${ }^{\star}$ No information available in five patients. severe cerebellar atrophy was more often found in the upper vermal region $(n=32,41 \%)$ than in the cerebellar hemispheres $(\mathrm{n}=16,20.5 \%)$ and in the lower vermal region $(n=15,19 \%)$. Table 1 shows the variables associated with cerebellar atrophy. All patients except two had been treated with PHT at some time before surgery. The medical records did not provide sufficient data for duration, dosing, and possible toxicity of PHT. Hence influence of PHT on the occurrence of cerebellar atrophy could not be evaluated.

Stepwise multiple regression analysis used all four factors significantly associated with cerebellar atrophy in the univariate tests as independent variables. Duration of epilepsy was the only factor without influence in this analysis, whereas age, history of GTCS, and intellectual impairment were significantly correlated with the presence of cerebellar atrophy.

\section{CEREBELLAR ATROPHY AND OUTCOME OF} SURGERY

The 78 patients were followed up for a mean of 14.6 (range 6-40) months. At the last follow up, group SF comprised 50 patients $(64 \cdot 1 \%(95 \%$ CI $52 \cdot 4-74 \cdot 7 \%))$, with 41 patients $(52 \cdot 6 \%(95 \%$ CI $40 \cdot 9-64 \cdot 0 \%))$ having no seizures and no auras, and nine patients (11.5\% (95\% CI 5.4-20.8\%)) having isolated auras only. Patients with cerebellar atrophy were more often found in group NSF than those without cerebellar atrophy $(p<0.01$, Fisher's exact test; table 2). For other factors associated with seizure outcome see table 2 .

Those five variables which showed a significant influence on outcome in univariate tests were included in a multiple stepwise logistic regression analysis. As shown in table 3, occurrence of GTCS within two years before surgery (highly significant) and cerebellar atrophy documented by MRI (marginally significant) remained the only factors which were related to outcome in group NSF. These two factors were able to correctly classify $75 \cdot 3 \%$ of the outcome.

\section{Discussion}

VARIABLES ASSOCIATED WITH CEREBELLAR ATROPHY

The pathogenesis of cerebellar atrophy in 
Figure 2 Influence of the variables cerebellar atrophy (CA) and occurrence of generalised tonic-clonic seizures two years before surgery (GTCS) on outcome of temporal lobe surgery, alone and in combination. In five patients, data about GTCS were not available. The percentage of patients remaining seizure free was lowest in group $C A+1$ GTCS + $(p=0.0001$, $v C A-/ G T C S-$,

Fisher's exact test),

followed by group $C A-1$

GTCS + $(p=0.057)$ and by group $C A+1$

GTCS $-(p>0 \cdot 1)+=$ present $;-=$ absent

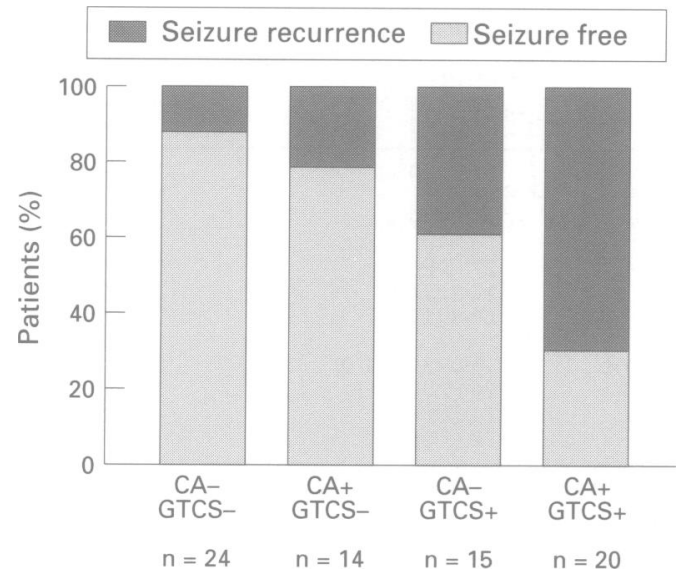

epileptic patients is controversial. Possible causes include frequent convulsive seizures, ${ }^{23}$ status epilepticus, ${ }^{122}$ subclinical epileptic seizure activity, ${ }^{11}$ treatment with PHT-with or without a history of acute intoxication $^{41012}$-and cerebellar damage preceding the manifestation of the epilepsy. ${ }^{40}$ In the present study, $45 \%$ of the 78 patients had moderate or severe cerebellar atrophy on MRI. Ney et al reported a frequency of cerebellar atrophy of $25 \%$ in a group of 36 patients with focal epilepsy. ${ }^{8}$ They had excluded patients with status epilepticus, anoxia, perinatal distress, and intellectual impairment (Wechsler adult intelligence scale-revised IQ < 70). The seizure frequency in their study was lower than in our group. This may explain the different frequencies of cerebellar atrophy.

Earlier studies on cerebellar atrophy in epileptic patients are difficult to compare, as CT was used ${ }^{525}$ and types of epilepsy were not noted. ${ }^{57}$ Age, history of GTCS, intellectual impairment, and duration of epilepsy were significantly correlated with the presence of cerebellar atrophy in our study, with the first three variables being confirmed as the main factors in a multiple regression analysis. These results differ from those of Ney et $a l,{ }^{8}$ probably due to exclusion criteria (see above) and small sample size in their investigation. The frequency of CPS was not significantly related to cerebellar atrophy in either study. Our findings of a correlation between intellectual impairment and cerebellar atrophy are in agreement with those of Botez et al, ${ }^{26}$ but the contribution of the cerebellum to cognition is a matter of debate. ${ }^{27}$

Our data lack sufficient information on prior treatments with PHT. Earlier studies found conflicting results with respect to an association between PHT and cerebellar atrophy. ${ }^{78}$ We think that the role of PHT in the pathogenesis of cerebellar atrophy cannot be resolved through a retrospective study, as high dose PHT treatment and severe epilepsy are variables which are closely related in most patients, as shown by Dam. ${ }^{23}$

\section{OUTCOME OF SURGERY}

Although we used a stricter definition of surgical success than commonly applied, ${ }^{28}$ overall surgical outcome in our cohort of patients with medically refractory temporal lobe epilepsy is in keeping with the results of an international multicentre survey. ${ }^{29} \mathrm{~A}$ total of $64 \cdot 1 \%$ of the patients were seizure free during the whole follow up period of 14.6 (SD 9) months. However, the follow up period was short. Studies investigating factors possibly influencing outcome are difficult to compare due to different outcome measures and different factors studied. Some of the investigations were based on a small sample size, ${ }^{30}{ }^{31}$ or included patients with extratemporal seizures. ${ }^{32}$

PREDICTORS OF OUTCOME: INFLUENCE OF CEREBELLAR ATROPHY AND OTHER FACTORS

This study investigated the role of cerebellar atrophy diagnosed by MRI as a possible predictive factor for recurrence of seizures after temporal lobe surgery. Since the first report of Cooke and Snider in $1955,{ }^{13}$ several experimental studies using electrical stimulation of the cerebellum, ${ }^{1533}$ cooling of the cerebellar cortex, ${ }^{14}$ or cerebellar ablation ${ }^{1617}$ showed inhibitory effects of the cerebellum on epileptic foci and seizures. As a consequence of these findings, cerebellar stimulation had been studied in patients with medically refractory seizures; however, without convincing effects. ${ }^{34}$ Nevertheless, structural damage of the cerebellum might reduce its inhibitory influence on seizure activity. This is suggested by the results of the present study, showing that significantly more patients with cerebellar atrophy had seizures after temporal lobe resection, compared with patients with a normal cerebellum. The proportion of patients with cerebellar atrophy was nearly twice as high in outcome group NSF than in group SF. No association between outcome and cerebral atrophy was found, suggesting that the relation between cerebellar atrophy and outcome is not a mere consequence of a more diffuse and non-specific damage.

Our finding that a higher proportion of group NSF patients had a history of GTCS confirms the results of previous reports. ${ }^{3035-37}$ Blume et al suggested that GTCS "may imply more widespread involvement of epileptogenesis". ${ }^{37}$ The GTCS occurring early in the course of epilepsy or before initiation of treatment might be of less importance for prognosis, whereas persistence of GTCS despite treatment could be an indicator of a more severe epilepsy. We therefore evaluated the occurrence of GTCS within two years before surgery. This variable seemed to be of greater importance than the mere occurrence of GTCS at any time preoperatively, as shown by the results of the multiple regression analysis (see below). Duncan and $\operatorname{Sagar}^{38}$ found no correlation between occurrence of GTCS at the time of assessment and outcome. However, if the different degrees of outcome would be considered, recalculation of the given numbers (table $3^{38}$ ) disclosed a significant relation between GTCS at the time of assessment and unfavourable outcome $(p=0.049$, two tailed, exact MannWhitney $U$ test). In addition, lack of agreement might be due to their outcome classification, which included patients with nocturnal seizures in the most favourable outcome group. 
In accordance with previous studies, ${ }^{30} 363940$ patients with a shorter duration of epilepsy showed better results after temporal lobe surgery. However, other authors did not confirm these findings. ${ }^{32} 3537$ Long duration of epilepsy as a negative prognostic factor has commonly been discussed in the context of secondary epileptogenesis in human temporal lobe epilepsy. ${ }^{39-41}$ Because we found a correlation between age at surgery and duration of epilepsy $(r=0.68, \quad \mathrm{p}<0.001$, Spearman's rank correlation), it seemed obvious that older age at surgery also significantly indicated seizure recurrence after surgery. This is in keeping with earlier reports. ${ }^{35-37}$

Studies relating surgical outcome to MRI findings showed that the prognosis of temporal lobe resection is greatly improved if a focal lesion or a mesiotemporal sclerosis can be demonstrated in MRI. ${ }^{42}$ 44 In the present study, the proportion of patients with lesions in group SF was higher, but did not reach significance. Salanova et al reported similar findings. ${ }^{40}$ We found no correlation between seizure free outcome and mesiotemporal sclerosis detected by MRI. This may be related to limited quality of earlier MRIs, as high resolution MRI was not available in our centre before July 1993.

With several variables significantly associated with outcome measures in univariate analyses, the multiple stepwise logistic regression procedure is useful for determining the relative importance of each variable, and to consider correlations among these variables. ${ }^{32}{ }^{37}$ Compared with our study, Dodrill et $a l^{32}$ and Blume et $a l^{37}$ evaluated several additional factors (for example, detailed neuropsychological data ${ }^{32}$ ), but did not investigate the possible predictive role of a cerebellar atrophy on outcome after surgery. For our results, logistic regression analysis disclosed two variables as the only predictive indicators for postoperative seizure recurrence: occurrence of GTCS within two years before surgery proved to be the most relevant factor, but cerebellar atrophy shown by MRI also seemed to be of prognostic value. As shown in fig 2 , a coincidence of both factors resulted in the highest proportion of group NSF patients. Blume et $\mathrm{al}^{37}$ underlined a worse seizure prognosis in patients with a history of GTCS in their multiple regression analysis, but did not evaluate GTCS occurring within two years before surgery.

Cerebellar atrophy has not been previously reported with respect to prognosis, and thus its possible predictive value must be confirmed in studies with larger cohorts of patients and longer follow up periods. If cerebellar atrophy proves to be a reliable indicator for recurrence of seizure after surgery, this will probably influence preoperative counselling, as cerebellar atrophy can easily be detected with MRI.

We thank Dr Lumiani and colleagues for providing MRI. The paper was presented in part at the 21 st International Epilepsy Congress, Sydney, Australia, 3-8 September 1995.

1 Spielmeyer $W$. Über einige Beziehungen zwischen Ganglienzellveränderungen und gliösen Erscheinungen, besonders am Kleinhirn. Zeitschrift für die gesamte
Neurologie und Psychiatrie 1920;54:1-38

2 Scholz W. Die Krampfschädigungen des Gehirns. Berlin, Göttingen, Heidelberg: Springer-Verlag, 1951.

3 Norman RM, Sandry S, Corsellis JAN. The nature and origin of patho-anatomical change in the epileptic brain. In Vinken PJ, Bruyn GW, eds. Handbook of clinical neurology. Amsterdam: North-Holland, 1974:611-20.

4 Dam M. Neuropathology of cerebellum. In: Wolf P, Dam M, Janz D, Dreifuss FE, eds. Advances in epileptology. 16th epilepsy international symposium. New York: Raven 16th epilepsy internatio

5 Kessler C, Henningsen H, Reuther R, Christian W. Zur Kleinhirnatrophie bei Epilepsiekranken: Eine computertomographische Untersuchung. Fortschr Neurol Psychiat tomographische

6 Roger J, Gambarelli-Dubois D. Neuropathological studies of the Lennox-Gastaut syndrome. In: Niedermeyer E, Degen R, eds. The Lennox-Gastaut syndrome. New York: Alan R Liss, 1988:73-93.

7 Botez MI, Attig E, Vezina JL. Cerebellar atrophy in epileptic patients. Can $\mathcal{F}$ Neurol Sci 1988;15:299-303.

8 Ney GC, Lantos G, Barr WB, Schaul N. Cerebellar atrophy in patients with long-term phenytoin exposure and epilepsy. Arch Neurol 1994;51:767-71.

9 Specht U, May TW, Rohde M, Wagner V, Schmidt RC Schütz M. Carbamazepine toxicity in focal epilepsy with and without cerebellar atrophy documented by MRI and without cerebellar atrophy docume

10 Ghatak NR, Santoso RA, McKinney WM. Cerebellar degeneration following long-term phenytoin therapy. Neurology 1976;26:818-20.

11 Dam M, Bolwing T, Hertz $M$, Bajorec J, Lomax $P$, Mouritzen Dam A. Does seizure activity produce purkinje cell loss? Epilepsia 1984;25:747-51.

12 Masur H, Elger CE, Ludolph AC, Galanski M. Cerebellar atrophy following acute intoxication with phenytoin. Neurology 1989;39:432-3.

13 Cooke PM, Snider RS. Some cerebellar influences on electrically-induced cerebral seizures. Epilepsia 1955;4:19-28.

14 Dow RS, Fernández-Guardiola A, Manni E. The influence of the cerebellum on experimental epilepsy. Electroof the cerebellum on experimental epilepsy.

15 Hutton JT, Frost JDJ, Foster J. The influence of the cerebellum in cat penicillin epilepsy. Epilepsia 1972;13: 401-8.

16 Gartside IB. The effects of cerebellectomy on a penicillin epileptogenic focus in the cerebral cortex of the rat Electroencephalogr Clin Neurophysiol 1978;44:373-9.

17 Paz C, Reygadas E, Fernández-Guardiola A. Amygdala kindling in totally cerebellectomized cats. Exp Neurol 1985;88:418-24.

18 Miller JW, Gray BC, Turner GM. Role of fastigial nucleus in generalized seizures as demonstrated by GABA agonist microinjections. Epilepsia 1993;34:973-8.

19 Hori A, Kazukawa S, Fujii T, Kurachi M. Lennox-Gastaut syndrome with and without Dandy-Walker malformasyndrome with and without Dand
tion. Epilepsy Res 1987;1:258-61.

20 Meencke H-J, Veith G. Neuropathologische Aspekte des myoklonisch-astatischen Petit mal (Lennox-Syndrom) In: Kruse R, ed. Epilepsie 84. Reinbek: Einhorn-Press Verlag, 1985:305-13.

21 Fried I, Spencer DD. Surgical aspects. In: Wyllie E, ed. The treatment of epilepsy: principles and practices. Philadelphia/London: Lea and Febiger, 1993:1075-83.

22 Cyr L, Francis K. Measures of clinical agreement for nominal and categorical data: the kappa coefficient. Comput Biol Med 1992;22:239-46.

23 Dam M. Number of purkinje cells in patients with grand mal epilepsy treated with diphenylhydantoin. Epilepsia 1970;11:313-20.

24 Meldrum BS, Vigouroux RA, Brierley JB. Systematic factors and epileptic brain damage. Prolonged seizures in tors and epileptic brain damage. Prolonged seizures in paralysed artifici

25 Specht U, Rohde M, May T, Schmidt RC, Meencke H-J, Wolf P. Cerebellar atrophy does not increase susceptibility to carbamazepine toxicity. Acta Neurol Scand 1994 89: $1-4$

26 Botez MI, Botez T, Elie R, Attig E. Role of the cerebellum in complex human behavior. Ital $\mathcal{f}$ Neurol Sci 1989 10:291-300

27 Daum I, Ackermann H. Cerebellar contributions to cognition. Behav Brain Res 1995;67:201-10.

28 Engel J, Jr, Van Ness PC, Rasmussen TB, Ojemann LM Outcome with respect to epileptic seizures. In: Engel JJ, ed. Surgical treatment of the epilepsies. 2nd ed. New York: Raven Press, 1993:609-21.

29 Engel J, Jr. Update on surgical treatment of the epilepsies. Summary of the second palm desert conference on the surgical treatment of the epilepsies (1992). Neurology surgical treatment

30 Bergen D, Morrell F, Bleck TP, Whisler WW. Predictors of success in surgical treatment of intractable epilepsy [abstract]. Epilepsia 1984;25:665.

31 Swartz BE, Tomiyasu U, Delgado-Escueta AV Mandelkern M, Khonsari A. Neuroimaging in temporal lobe epilepsy: test sensitivity and relationship to pathology and postoperative outcome. Epilepsia 1992;33 624-34

32 Dodrill CB, Wilkus RJ, Ojemann GA, Ward AA, Wyler $\mathrm{AR}$, van Belle $\mathrm{G}$, et al. Multidisciplinary prediction of seizure relief from cortical resection surgery. Ann Neurol 1986;20:2-12.

33 Iwata K, Snider RS. Cerebello-hippocampal influences on 
the electroencephalogram. rauss GL, Fisher RS. Cerebellar and thalamic stimulation for epilepsy. In: Devinsky O, Beric A, Dogali M, eds. Electrical and magnetic stimulation of the brain and spinal cord. New York: Raven Press, 1993:231-45.

35 Bengzon AR, Rasmussen T, Gloor P, Dussault J, Stephens $M$. Prognostic factors in the surgical treatment of temporal lobe epilepsy. Neurology 1968;18:717-31

36 Jensen I. Temporal lobe epilepsy: types of seizures, age, and surgical results. Acta Neurol Scand 1976;53:335-57.

37 Blume WT, Desai HB, Girvin JP, McLachlan RS, Lemieux JF. Effectiveness of temporal lobectomy measured by yearly follow-up and multivariate analysis. $\mathcal{F}$ Epilepsy yearly follow-up

38 Duncan JS, Sagar HJ. Seizure characteristics, pathology, and outcome after temporal lobectomy. Neurology 1987; 37:405-9.

39 Engel J, Jr, Cahan L. Potential relevance of kindling to human partial epilepsy. In: Wada J, ed. Kindling 3. New York: Raven Press, 1986:37-51
40 Salanova V, Markand ON, Worth R. Clinical characteristics and predictive factors in 98 patients with complex partial seizures treated with temporal resection. Arch Neurol 1994;51:1008-13.

41 Morrell F, Smith MC, Detoledo-Morrell L. Secondary epileptogenesis and kindling. In: Wyllie E, ed. The treatment of epilepsy: principles and practices. Philadelphia/ London: Lea and Febiger, 1993:126-144.

42 Kuzniecky R, Burgard S, Faught E, Morawetz R, Bartolucci A. Predictive value of magnetic resonance imaging in temporal lobe epilepsy surgery. Arch Neurol 1993;50:65-9.

43 Garcia PA, Laxer KD, Barbaro NM, Dillon WP. Prognostic value of qualitative magnetic resonance imaging hippocampal abnormalities in patients undergoing temporal lobectomy for medically refractory seizures. Epilepsia 1994;35:520-4.

44 Berkovic SF, McIntosh AM, Kalnins RM, Jackson GD, Fabinyi GCA, Brazenor GA, et al. Preoperative MRI predicts outcome of temporal lobectomy: an actuarial analysis. Neurology 1995;45:1358-63. 